\title{
Omega 3 polyunsaturated fatty acids and body weight
}

\author{
Emilio Martínez-Victoria* and María Dolores Yago \\ Institute of Nutrition and Food Technology and Department of Physiology, University of Granada, Granada, Spain
}

\section{Abstract}

In animal studies, $n-3$ PUFA have been shown to influence body composition and to reduce the accumulation of body fat, thereby affecting body weight homeostasis. In addition, it has been suggested that an additional supply of $n-3$ PUFA during pregnancy or lactation, or both, would have a beneficial effect on birth weight and infant growth and development. The purpose of the present study was to systematically review interventional clinical trials on the effects of dietary $n-3$ PUFA supplementation on body weight in adult subjects and in infants whose mothers were supplemented with these fatty acids during pregnancy and/or lactation. A systematic search, focused on $n-3$ PUFA and body weight, and limited to controlled clinical trials, was performed in different databases. The quality of all included studies was assessed against set criteria, and results of eligible trials were compared. There were few studies targeting this topic. In adults, all of the five studies included, except for one, show no change in body weight by dietary supplementation with $n-3$ PUFA. Within those trials conducted in pregnant and/or lactating women in which a main outcome was birth weight or growth in infancy, two showed a modest increase in birth weight and the rest showed no effect. None of the trials showed an effect of maternal $n$ - 3 PUFA supplementation on infant's weight at the short term. However, it should be noted that a number of limitations, including a variety of experimental designs, type and doses of $n-3$ PUFA, and high attrition rates, among others, make impossible to draw robust conclusions from this review.

\section{Key words: Fatty acids, omega-3: Body weight: Birth weight: Growth: Systematic review}

Obesity is an important health problem of the modern world. The incidence of this condition has tripled during the past 20 years and the trend continues to be upward. Because overnutrition leads to obesity, manipulation of dietary nutrient content is a logical means of alleviating this problem. The above justifies the concern about body weight and about how this is influenced by a number of dietary constituents ${ }^{(1)}$. Consumption of $n-3$ PUFA is associated with various health benefits. Along with lowering of plasma TAG, $n-3$ PUFA also improve insulin sensitivity and reduce blood pressure, inflammation, thrombosis and arrhythmia, contributing to their role in lowering the risk of CVD and diabetes. In animal studies, $n$-3 PUFA have been shown to influence body composition and to reduce the accumulation of body fat, thereby affecting body weight homeostasis ${ }^{(2,3)}$.

Considerable attention has been paid to the effect of longchain n-3 PUFA on pregnancy outcome ${ }^{(4)}$. Intake of longchain $n-3$ PUFA or fish oil by pregnant women has been associated with an increased birth weight, together with a reduced risk of premature birth and other complications during pregnancy ${ }^{(5)}$. It has been proposed that long-chain $n-3$ PUFA are limiting factors for the growth and development of newborns and young children ${ }^{(6)}$. Most of this information comes from observational studies. Moreover, intervention trials involving maternal fish oil supplementation during pregnancy and lactation have yielded inconsistent results likely due to the sample size and heterogeneity in long-chain $n-3$ PUFA (both type and quantity) ${ }^{(4,7,8)}$.

However, there has been no systematic review that evaluates, in humans, the results of randomized controlled trials studying body weight changes after the administration of $n-3$ PUFA as supplements or as part of an enriched diet. The objective of the systematic review was to determine the effect of $n$-3 PUFA supplementation or diets enriched in $n$ - 3 PUFA on body weight in adults, and on birth weight and growth in infants whose mothers were supplemented during pregnancy and/or lactation.

\section{Methods}

A systematic literature search was performed in March and April 2011. The literature search was conducted in Medlars Online International Literature (MEDLINE), via PubMed $($ C and via OvidSPC (Ovid MEDLINE); EMBASEC); Latin American and Caribbean Health Sciences Literature (LILACS) and ISI Web of Knowledge using the following terms: "Fatty acids, omega-3"[Major] OR "alpha-linolenic acid"[Mesh] OR "docosahexaenoic acids"[Mesh] OR "eicosapentaenoic acid" [Mesh] AND ("body weight"[Major] OR "birth weight"[Mesh] OR "body weight changes"[Mesh] OR "weight gain"[Mesh] OR "weight loss"[Mesh] OR "fetal weight"[Mesh] OR "overweight"[Mesh] OR "obesity”[Mesh] OR "obesity, morbid”[Mesh] 
OR "Body Composition"[Major]) AND ("humans"[MeSH Terms] AND (Clinical Trial[ptyp] OR Randomized Controlled Trial[ptyp])). In total, 149 articles were selected. After reading the title or abstract of all these articles, two reviews (references) and the literature list of the selected papers, eleven were included in the results. The articles were reviewed by at least two reviewers and were taken into account for the selection criteria listed on the $\operatorname{JADAD}^{(9)}$, a procedure to independently assess the methodological quality of a clinical trial. Studies with a JADAD score $\geq 3$ were included. Trials in which n-3 PUFA were administered combined with other PUFA (without a group supplied with $n-3$ PUFA alone) were excluded. In addition, for the adult studies we only considered those having body weight as the primary outcome. Studies involving body weight changes in cancer and HIV patients were excluded. For the infant studies, we focused our attention on trials in which the intervention was applied during pregnancy and/or lactation and had growth measures at birth (birth weight) or infant growth as primary outcomes. Trials in women with high-risk pregnancies were not included. Reviewers extracted data from the published articles.

\section{Results and discussion}

\section{Studies in adults}

An outline of the adult studies that were included in this review $^{(10-14)}$ is presented in Table 1 . As it can be observed, the duration of the intervention was different (in two of the trials the intervention was applied during 2 months, in one during 3 months, and in the remaining two trials during 6 months) and, even though all of them used EPA and DHA as $n-3$ PUFA, the doses of treatment and proportions were variable. Likewise, the source of $n-3$ PUFA varied between trials. In some cases $n$-3 PUFA were derived from food (fish) whereas in other cases fatty acids from fish oil were supplied as pharmaceutical preparations (capsules) with different EPA/ DHA ratios. There was also variation in the placebo type, which consisted of different oils (soybean, corn, sunflower and paraffin oil) or an undetermined oil composed of $n-6$ PUFA (linoleic acid) and MUFA (oleic acid).

Baseline characteristics of participating subjects were distinct, although all trials included either overweight or obese subjects with BMI $>25 \mathrm{~kg} / \mathrm{m}^{2}$, without reaching $40 \mathrm{~kg} / \mathrm{m}^{2}$ (morbid obesity). In one trial ${ }^{(10)}$, the subjects did not have another associated disorder whereas the rest included patients having one or more cardiovascular risk factors ${ }^{(13)}$, type 2 diabetes mellitus ${ }^{(12)}$, hyperinsulinaemia ${ }^{(14)}$ or some features of metabolic syndrome ${ }^{(11)}$. Among the five trials included, two of them considered only females ${ }^{(12,14)}$.

In most trials, the intervention involved a hypocaloric diet or a weight-loss programme. In addition, two of them incorporated scheduled exercising ${ }^{(10,13)}$, and another one advise to increase physical activity as a co-adjuvant of the weightloss programme or to aid in weight maintenance.

Of the two studies incorporating scheduled exercising, the trial by DeFina et al. ${ }^{(10)}$ aimed to explore whether the addition of supplemental $n$-3 PUFA in conjunction with diet and exercise would provide greater weight loss in overweight and obese subjects. The authors found an average loss $>5 \%$ of initial body weight, although there were no significant differences between the $n$-3 PUFA supplemented group and the placebo group. Also, a similar decrease in total caloric intake was reported in both the supplement and placebo groups. However, the results of this trial are based on completion of two 3-d food diaries (including 1 weekend day) and of exercise logbooks for each session, both self-reported. In this sense, it should be noted that these self-report measures increase the risk of overreporting energy expenditure and underreporting energy intake ${ }^{(15,16)}$.

The study by Hill et al. ${ }^{(13)}$, the other study including a prescribed programme of regular physical activity, had a different experimental design. The authors examined the individual and combined effects of $n$-3 PUFA supplements and regular exercise by establishing four groups: fish oil ( $n$ 17), fish oil plus exercise ( $n$ 16), placebo ( $n$ 18), and placebo plus exercise ( $n$ 14). Energy intake was assessed by completion of four 3-d weighed food records (1 weekend), and physical activity by monitoring of regular participation in supervised exercise sessions as well as completion of physical activity diaries. As in the above trial, no differences were observed in body weight between $n$-3 PUFA-supplemented and placebo groups (with or without exercise). Both fish oil and exercise independently reduced body fat, although the effect was modest. The authors also report a beneficial influence of $n-3$ PUFA on selected metabolic and cardiovascular factors (TAG, HDL cholesterol, endothelium-dependent arterial vasodilation). Compliance was assessed by capsule count, erythrocyte FA analysis, monitoring of regular participation in supervised exercise sessions, and completion of weighed food records and physical activity diaries.

Marked differences in design and methodology exist between the two trials that comprise scheduled exercising, all of which may affect the final results. In the trial by DeFina et $a l .^{(10)}$ the intervention period lasted for 24 weeks, while the intervention was applied during only 12 weeks in the Hill et $a l^{(13)}$ trial. Diets in the trial by DeFina et al. ${ }^{(10)}$ were calorie-controlled, but subjects in the trial by Hill et $a l .{ }^{(13)}$ were instructed to maintain their normal diet during the study, the intervention involving only the physical activity and the presence or absence of the $n$ - 3 PUFA supplement. The dose of $n-3$ PUFA provided to the treatment groups in the trial by Hill et $a l .{ }^{(13)}$ were lower than in the trial by DeFina et $a l .{ }^{(10)}$ and, moreover, the EPA/DHA ratios were different $(<1$ in the former and $>1$ in the latter). This fact is to be noted, since a number of studies suggest that different long-chain $n$-3 PUFA, particularly EPA and DHA, may have differential effects on inflammation, cardiovascular risk factors and blood lipids ${ }^{(17)}$, and in depressive disorders ${ }^{(18)}$.

The studies by Kabir et al. ${ }^{(12)}$ and Krebs et al. ${ }^{(14)}$ focused on body weight changes following the administration of $n-3$ PUFA supplements in overweight or obese women, either postmenopausal women with type 2 diabetes without hypertriacylglycerolemia ${ }^{(12)}$ or hyperinsulinaemic ${ }^{(14)}$.

Kabir and colleagues ${ }^{(12)}$ conducted their study to evaluate whether the intake of a moderate dose of $n$ - 3 PUFA, which 
Table 1. Human intervention trials in adults with an increased intake of $n-3$ PUFA on body weight

\begin{tabular}{|c|c|c|c|c|}
\hline Publication & Participants & Design and duration & Intervention & Outcomes \\
\hline $\begin{array}{l}\text { DeFina } \\
\text { et al. }{ }^{(10)}\end{array}$ & $\begin{array}{l}128 \text { sedentary overweight or obese } \\
\text { adult men and women }\end{array}$ & $\begin{array}{l}6 \text { months, Placebo-controlled, } \\
\text { randomized clinical trial. }\end{array}$ & $\begin{array}{l}\text { Intervention: } 5 n-3 \text { capsules daily ( } 1000 \mathrm{mg} \\
\text { EPA/200 mg DHA per dose). ( } n 64) \\
\text { Placebo: } 5 \text { capsules daily soybean and corn } \\
\text { oil at a ratio of } 1: 1 . \text { ( } n 64) \\
\text { Aerobic exercise and dietary counseling. }\end{array}$ & $\begin{array}{l}\text { No significant weight-reduction benefit was } \\
\text { seen with the addition of } n-3 \text { fatty acid }\end{array}$ \\
\hline $\begin{array}{l}\text { Thorsdottir } \\
\quad \text { et al. }\end{array}$ & $\begin{array}{l}278 \text { adult overweight or obese individ- } \\
\text { uals, waist circumference } \geq 94 \text { and } \\
\geq 80 \mathrm{~cm} \text { for men and women }\end{array}$ & $\begin{array}{l}\text { Randomized, Controlled Intervention } \\
\text { Trial. } \\
8 \text { consecutive weeks, energy- } \\
\text { restricted diet. }\end{array}$ & $\begin{array}{l}4 \text { groups: Control, no seafood (6 sunflower oil } \\
\text { capsules/d) }(n 66) \text {. } \\
\text { Lean fish. }(n 70) \\
\text { Fatty fish. }(n 74) \text {. Fish oil }(6 \text { capsules } / \mathrm{d}(n 68) \\
n-3 \text { PUFA content: from } 0 \text { to } 3.0 \mathrm{~g} / \text { day. }\end{array}$ & $\begin{array}{l}\text { Weight loss was significantly greater in the } \\
\text { groups receiving fish or fish oil in male sub- } \\
\text { jects only. }\end{array}$ \\
\hline $\begin{array}{l}\text { Kabir } \\
\quad \text { et al. }{ }^{(12)}\end{array}$ & $\begin{array}{l}26 \text { postmenopausal women with type } \\
2 \text { diabetes }\end{array}$ & $\begin{array}{l}2 \text { months double blind Randomized } \\
\text { Parallel trial. }\end{array}$ & $\begin{array}{l}\text { Supplements: } 3 \mathrm{~g} / \mathrm{d} \text { of either fish oil (containing } \\
1.8 \mathrm{~g} n-3 \text { PUFA: } 1.08 \mathrm{~g} \text { EPA acid and } 0.72 \mathrm{~g} \\
\text { DHA) }(n 12) \text { or placebo (paraffin oil) }(n 14)\end{array}$ & $\begin{array}{l}\text { Total body weight remained unchanged. } \\
\text { Total fat mass and subcutaneous adipo- } \\
\text { cyte diameter were lower in the fish oil } \\
\text { group than in the placebo group. }\end{array}$ \\
\hline $\begin{array}{l}\text { Hill } \\
\quad \text { et } a l .{ }^{(13)}\end{array}$ & $\begin{array}{l}65 \text { Sedentary overweight or obese } \\
\text { adult with cardiovascular risk factors }\end{array}$ & $\begin{array}{l}12 \text { weeks double-blind randomized } \\
\text { controlled parallel intervention trial }\end{array}$ & $\begin{array}{l}\text { Groups: } 4 \text {. With and without regular exercise } \\
\text { Experimental: } 6 \mathrm{~g} / \mathrm{d} \text { tuna fish oil }(260 \mathrm{mg} \text { DHA } \\
\text { and } 60 \mathrm{mg} \text { EPA) } \\
\text { Placebo: } 6 \mathrm{~g} / \mathrm{d} \text { sunflower oil }\end{array}$ & $\begin{array}{l}\text { Fish oil supplementation and regular exercise } \\
\text { significantly reduced body fat but not body } \\
\text { weight. }\end{array}$ \\
\hline $\begin{array}{l}\text { Krebs } \\
\quad \text { et } \text { al. }^{(14)}\end{array}$ & $\begin{array}{l}93 \text { overweight or obese and hyper- } \\
\text { insulinaemic female subjects }\end{array}$ & $\begin{array}{l}24 \text { weeks double blind randomized } \\
\text { controlled intervention trial. } \\
\text { Control group: no weight-loss and } \\
\text { placebo oil. } \\
\text { Weight-loss group: energy-restricted } \\
\text { diet intervention with either sup- } \\
\text { plemental } n-3 \text { PUFA or placebo oil }\end{array}$ & $\begin{array}{l}\text { Five } 1 \mathrm{~g} \text { oil capsules per day } 1.3 \mathrm{~g} \text { EPA and } \\
2.9 \mathrm{~g} \text { DHA per day. Placebo } 1 \mathrm{~g} \text { oil capsules } \\
\text { per day, containing } 2 \cdot 8 \mathrm{~g} / \mathrm{d} \text { of } 18: 2 \mathrm{n}-6 \text { and } \\
1.4 \mathrm{~g} / \mathrm{d} \text { of } 18: 1 \mathrm{n}-9\end{array}$ & $\begin{array}{l}\text { There were no significant differences in body } \\
\text { weight at any time point between the two } \\
\text { weight-loss intervention groups. }\end{array}$ \\
\hline
\end{tabular}


is generally prescribed in France, might influence in their study subjects the adiposity and several parameters related to type 2 diabetes and to the secretory pattern and gene expression in adipose tissue. Before and after the intervention, 7-d food diaries were completed for measurement of food intake, being assumed by the authors the risk of underestimating true calorie intake ${ }^{(16)}$. Physical activity of the participants was not controlled, either before or during the intervention period, which could have affected the analysis of anthropometric changes. Although body weight did not differ significantly between the 2 treatment groups ( $n-3$ PUFA and placebo), both total fat mass and adipocyte size in subcutaneous abdominal adipose tissue were significantly reduced by $3.5 \%$ and $6 \%$, respectively, after $n$-3 PUFA treatment compared with placebo.

The experimental design in the trial by Krebs et al. ${ }^{(14)}$, conducted in hyperinsulinaemic women, is different to that used by Kabir et al. ${ }^{(12)}$, given that they included three experimental groups: a control group (no weight-loss programme plus placebo treatment) ( $n$ 39) or one of two weight-loss intervention groups with either supplemental $n$-3 PUFA ( $n$ 39) or placebo ( $n$ 38). The intervention period comprised two phases, a first 12-week weight-loss phase (which in turn consisted of a 5week intervention for acute weight loss followed by a 7-wk period of staged re-introduction of meals), and a 12-week weight maintenance phase. The authors aimed to examine the hypothesis that increases in $n$-3 PUFA intake, combined with a reduction in energy intake, may have synergistic effects on weight-loss, insulin sensitivity and CVD risk factors. Again, energy intake and physical activity during the intervention were poorly controlled, being supported only by group sessions where the participants received dietary advice and guidance for physical activity promotion, and lacking ratification by standardised measures (food diary, exercise logs, etc.). This study shows that both weight-loss groups showed a significant reduction in body weight at 12 weeks and 24 weeks compared to baseline. However, there were no significant differences in body weight at any time point between the subjects supplemented with $n-3$ PUFA and those given placebo. Opposite to Kabir et al. ${ }^{(12)}$, no effect of $n-3$ PUFA was noted on lean mass, total fat mass or abdominal fat. This trial, apart from an inadequate control of food intake and physical activity, suffered from a high attrition rate not equal across the groups, which would have led to loss of statistical power.

The two studies conducted in women ${ }^{(12,14)}$, apart from the above mentioned, differed in the dose of fatty acids provided to the treatment group. Thus, whereas the diabetic women ${ }^{(12)}$ received $0.72 \mathrm{~g} / \mathrm{d}$ DHA and $1.08 \mathrm{~g} / \mathrm{d} \mathrm{EPA}$, the doses for hyperinsulinaemic women ${ }^{(14)}$ were greater $(2.9 \mathrm{~g} / \mathrm{d}$ DHA and $1.3 \mathrm{~g} / \mathrm{d}$ EPA) and with an opposite EPA/DHA ratio, which may have an impact on the biological effects, as mentioned earlier ${ }^{(17,18)}$.

The trial by Thorsdottir et al. ${ }^{(11)}$ is part of a large multicenter study, SEAFOODplus. The main outcome of this randomized controlled trial was weight loss in overweight and obese subjects with abdominal adiposity, according to waist circumference. The subjects were instructed to follow an energyrestricted diet while being assigned to four diets varying in types of dietary protein and amount of $n-3$ PUFA, a control group (no seafood plus placebo capsules) and three experimental groups. In two of them the subjects consumed three 150 g-portions of fish per week, either lean fish (cod) or fatty fish (salmon). A fourth group was allocated to fish oil capsules. The intervention lasted for 8 weeks. The EPA/DHA ratio of the different treatments is not reported by the authors.

The main finding of the trial by Thorsdottir et $a l .^{(11)}$ is that men (and not women) following an energy-restricted diet for 8 weeks containing lean or fatty fish or fish oil lost more weight (approximately $1 \mathrm{~kg}$ ) during weeks $1-4$ than those receiving an isocaloric energy-restricted diet without marine food. Once again, we find that the measures to record food intake and physical activity do not allow to precisely determine real intake and physical activity level of the participants. In a later study by this group ${ }^{(19)}$, also part of SEAFOODplus, it was shown that subjects with a high $n$-3 PUFA consumption (salmon group and fish oil capsules group, where longchain $n$-3 PUFA intake was $>1.3 \mathrm{~g} / \mathrm{d}$ ) reported a greater postprandial satiety than those with a low one (control group and cod group, where long-chain $n$-3 PUFA intake was $<0.26 \mathrm{~g}$ / d). The authors conclude that inclusion of long-chain $n-3$ PUFA could improve compliance to changes in dietary habits in patients aiming a weight loss.

Of the five studies in adults, adverse effects occurring in conjunction with the intervention were reported only in one trial $^{(10)}$. These events were all gastrointestinal in nature ( 3 individuals in the supplement group and 2 in the placebo group). All symptoms resolved when the research team suggested administration changes, although 2 participants withdrew from the study.

As a whole, the results of the 5 trials that met our inclusion criteria do not provide us with data robust enough as to conclude that $n$-3 PUFA can modify, and particularly reduce, body weight. Marked differences in experimental design, intervention type and duration, baseline characteristics of the participants (degree of obesity, associated condition, etc.), attrition rate, dose of $n$ - 3 PUFA and EPA/DHA ratio, make the results inconclusive and, in some cases, discordant. It is worth noting that a major limitation of these trials is the absence of an appropriate and precise control of energy intake and physical activity, two decisive factors in order to assess weight loss.

\section{Studies in pregnant/lactating women}

Two long-chain PUFA, DHA and arachidonic acid (AA), are important to foetal and infant growth and development. Deposition is especially high during the last trimester of pregnancy and first months of life ${ }^{(20)}$, when an insufficient amount can lead to adverse effects or irreversible damage ${ }^{(21)}$. Both $n-3$ and $n-6$ PUFA required for the foetus are supplied during pregnancy by preferential placental transfer ${ }^{(22,23)}$. Although both precursor essential fatty acids and preformed longchain PUFA can be transported, there is a preferential transfer of the latter form ${ }^{(24)}$. The foetus depends, therefore, on a maternal supply of long-chain PUFA. It has also been suggested in observational studies ${ }^{(25,26)}$ that a greater intake of long-chain PUFA, particularly of the $n-3$ series, DHA and 
EPA, may have a beneficial effect on pregnancy outcomes, including duration of gestation and infant weight at birth.

The concentration of $n-3$ PUFA in human milk is related to maternal $n$-3 PUFA status, which varies widely ${ }^{(27)}$. Supplementation of lactating women with $n-3$ PUFA increases breast milk content of $n-3$ PUFA $^{(28)}$. Several authors have reported that an additional supply of $n-3$ PUFA during pregnancy or lactation, or both, would improve an infant's later cognitive and visual development ${ }^{(29)}$.

In this part of the review, we aimed to elucidate the effect of $n$-3 PUFA supplementation during pregnancy and/or lactation on birth weight or infant growth. Trials examining only the long-term effects on infant growth (i.e. months or years after the intervention had finished) were not included. Although investigators in some of the included trials reported long-term growth effects, we have considered only that data obtained during or immediately after the supplemented lactation period $^{(4,7,8)}$

The characteristics of the included trials are summarized in Table 2. A total of 6 trials were included. The duration, sources and amounts of $n-3$ PUFA varied between trials. In three of the trials $^{(30-32)}$ the intervention was applied during gestation, in two trials ${ }^{(4,8)}$ the intervention was applied during pregnancy and lactation ( 3 mo post-delivery), and in one trial maternal supplementation was provided only during the first 4 mo of lactation $^{(7)}$. Trials supplementing pregnant women ${ }^{(4,8,30-32)}$ differed in the starting time of intervention, beginning as early as 18 week of gestation ${ }^{(4,32)}$ or as late as week 30 of gestation $^{(30)}$. The nature of supplements was varied. Three of the studies $^{(4,7,30)}$ used fish oil as supplement (thus providing both EPA and DHA), whereas the remaining three ${ }^{(8,31,32)}$ evaluated the role of just DHA, either prepared from fish oil ${ }^{(8)}$, in the form of DHA-enriched eggs ${ }^{(31)}$ or of algal origin ${ }^{(32)}$. There was also a great variability between the studies in relation to the doses of treatment and the EPA/DHA ratio (in those trials where both EPA and DHA were administered). In the studies with fish oil supplementation ${ }^{(4,7,30)}$, the daily amount of DHA plus EPA varied between $1410 \mathrm{mg} / \mathrm{d}^{(7)}$ and $2200 \mathrm{mg} / \mathrm{d}^{(30)}$, with EPA/DHA ratios ranging between $0 \cdot 7^{(4)}$ and $1 \cdot 4^{(30)}$. In those trials supplementing only $\mathrm{DHA}^{(8,31,32)}$, the doses of treatment varied from a minimum $137 \mathrm{mg} \mathrm{DHA} / \mathrm{d}^{(31)}$ and a maximum $400 \mathrm{mg} \mathrm{DHA} / \mathrm{d}^{(32)}$. It is to mention that there were also differences among the studies concerning the nature of the control group, although a predominance of olive oil as a control oil of has been found ${ }^{(7,30,32)}$

A first question to analyse is whether or not $n$-3 PUFA supplementation during pregnancy affects neonate weight at birth. Five trials have to be considered ${ }^{(4,8,30-32)}$. In the trial by Olsen et al. ${ }^{(30)}$, 533 pregnant Danish women were randomly assigned to receive either $4 \mathrm{~g} / \mathrm{d}$ fish oil (920 mg DHA/ d plus $1280 \mathrm{mg} \mathrm{EPA} / \mathrm{d}, n$ 266) or $4 \mathrm{~g} / \mathrm{d}$ olive oil ( $n$ 136) from wk 30 of gestation to delivery. The authors included also a second control group that received no supplement ( $n$ 131). However, as the authors themselves mention in their article, the fish oil versus olive oil comparison offered the best controlled and most valid comparison for estimating the effects of fish oil, because olive oil supplementation possibly prevented self-supplementation with fish oil and increased fish consumption (which was reported more often in the no oil group). After adjustment for sex and parity, women in the fish oil group had heavier babies at birth (mean difference: 107 g, 95\% CI 1, 214) compared with women in the olive oil group. This effect was largely attributed by the authors to the longer gestation in the fish oil group (mean difference $4 \mathrm{~d}, 95 \%$ CI 1.5, 6.4), since the difference became much smaller after adjusting for this factor. Importantly, when the differences in duration of gestation were stratified according to fish consumption at entry (estimated by a food frequency questionnaire) the effect of fish oil was strongest in women who had low fish consumption, suggesting the existence of a "saturation level", i.e. an inverse relationship between the $n$-3 PUFA maternal status at recruitment and the response to supplementation.

Helland and colleagues ${ }^{(4)}$ performed a study in which Norwegian women ( $n$ 590) were randomized to receive either $10 \mathrm{ml} / \mathrm{d}$ of cod liver oil (1183 mg DHA plus $803 \mathrm{mg}$ EPA, $n$ 301) or corn oil supplementation ( $10 \mathrm{ml} / \mathrm{d}, n 289)$ beginning at 18 wk of gestation up to three months after delivery. In this study, neither infant birth weight nor duration of gestation increased when women were supplemented with $n$-3 PUFA The dose of treatment in this study was high and in the same range as the dose supplied in the trial by Olsen et $a l .^{(30)}(2000-2200 \mathrm{mg} / \mathrm{d}$, sum of DHA plus EPA). However, the latter researchers ${ }^{(30)}$, despite a shorter intervention period (from wk 30) found a significant effect on birth weight whereas Helland et al. ${ }^{(4)}$ who started the supplementation at $18 \mathrm{wk}$, observed no effect. The differences may be attributable to several factors: 1 ) A different EPA/DHA ratio (1.4 in the trial by Olsen $e t a l{ }^{(30)}$ and 0.7 in the trial by Helland et $a l^{(34)}$ ), which may exert a differential influence on some biological parameters, as noted before. 2) Choice of control group. While Olsen et $a l^{(30)}$ used olive oil as placebo, Helland et $a l^{(4)}$ employed corn oil, rich in linoleic acid. Assessment of food intake at start ${ }^{(4)}$ revealed that intake of $n-6$ PUFA was below what had been found in other populations ${ }^{(33)}$. Since arachidonic acid is important for foetal development ${ }^{(20,34)}$, women in the control group were possibly receiving a beneficial supplement in terms of infant birth weight. In contrast, intake of $n-3$ PUFA in the participating Norwegian women at enrolment was high ${ }^{(4)}$. If a "saturation level" for the influence of $n-3$ PUFA on gestation length and birth weight exists, an attenuated response should be expected in the $n$-3 PUFA-supplemented group. It is, then, possible that the previous maternal fatty acid status combined with the choice of the placebo may account for the lack of effect of $n-3$ PUFA in this trial ${ }^{(4)}$.

In the other three trials where the intervention was applied during pregnancy, supplementation comprised only $\mathrm{DHA}^{(8,31,32)}$. The study by Bergmann et al. ${ }^{(8)}$ commenced with three treatment groups, a first group receiving a basic supplement consisting of vitamins and minerals, a second group receiving the basic supplement plus a prebiotic (fructooligosaccharide, FOS), and a third group receiving the basic supplement plus FOS plus $200 \mathrm{mg}$ DHA (prepared from fish oil). Subjects were 144 pregnant German women ( $n 48$ per group) and the intervention was applied from 21 
Table 2. Outline of included studies in pregnant/lactating women

\begin{tabular}{|c|c|c|c|c|c|c|}
\hline & Olsen et al. ${ }^{(30)}$ & Helland et al. ${ }^{(4)}$ & Smuts et al. ${ }^{(31)}$ & $\begin{array}{l}\text { Ramakrishnan } \\
\text { et al. }{ }^{(32)}\end{array}$ & Bergmann et al. ${ }^{(8)}$ & Lauritzen et al. ${ }^{(7)}$ \\
\hline Design & $\begin{array}{l}\text { Randomized double-blind } \\
\text { parallel study }\end{array}$ & $\begin{array}{l}\text { Randomized double-blind par- } \\
\text { allel study }\end{array}$ & $\begin{array}{l}\text { Randomized double-blind } \\
\text { parallel study }\end{array}$ & $\begin{array}{l}\text { Randomized double- } \\
\text { blind parallel study }\end{array}$ & $\begin{array}{l}\text { Randomized double-blind } \\
\text { parallel study }\end{array}$ & $\begin{array}{l}\text { Randomized double-blind } \\
\text { parallel study }\end{array}$ \\
\hline Participants & Healthy pregnant women & $\begin{array}{l}\text { Healthy pregnant women 19- } \\
35 \text { y old, nulli- or primipar- } \\
\text { ous, with single pregnancies } \\
\text { and intention to breastfeed } \\
\text { - Healthy, nonpremature } \\
\text { infants }\end{array}$ & $\begin{array}{l}\text { Healthy pregnant women } \\
16-36 \text { y old, with sin- } \\
\text { gleton gestation, able } \\
\text { and willing to consume } \\
\text { eggs }\end{array}$ & $\begin{array}{l}\text { Healthy pregnant } \\
\text { women } 18-35 \text { y } \\
\text { old }\end{array}$ & $\begin{array}{l}\text { - Healthy pregnant Cauca- } \\
\text { sian women at least } 18 \\
\text { y old, willing to breast- } \\
\text { feed for a minimum } \\
3 \text { mo } \\
\text { - Healthy, nonpremature } \\
\text { infants }\end{array}$ & $\begin{array}{l}\text { - Healthy pregnant women in } \\
\text { the } 8^{\text {th }} \mathrm{mo} \text { of gestation with } \\
\text { BMI }<30 \mathrm{~kg} / \mathrm{m}^{2} \text { and intention } \\
\text { to breastfeed for at least } 4 \mathrm{mo} \\
\text { - Healthy, term, singleton infants } \\
\text { with normal weight for } \\
\text { gestation }\end{array}$ \\
\hline $\begin{array}{l}\text { Intervention } \\
\text { duration }\end{array}$ & Wk 30 until delivery & Wk 18 until $3^{\text {rd }}$ mo of lactation & Wk 24-28 until delivery & $\begin{array}{l}\text { Wk 18-22 until } \\
\text { delivery }\end{array}$ & $\begin{array}{l}\text { Wk } 21 \text { until } 3^{\text {rd }} \text { mo of } \\
\text { lactation }\end{array}$ & Delivery until $4^{\text {th }}$ mo of lactation \\
\hline $\begin{array}{l}\text { Intervention } \\
\text { type and } \\
\text { dose }\end{array}$ & $\begin{array}{l}\text { Fish oil }(4 \mathrm{~g} / \mathrm{d}): 920 \mathrm{mg} / \mathrm{d} \\
\text { DHA }+1280 \mathrm{mg} / \mathrm{d} \mathrm{EPA}\end{array}$ & $\begin{array}{l}\text { Cod liver oil }(10 \mathrm{ml} / \mathrm{d}): \\
1183 \mathrm{mg} / \mathrm{d} \mathrm{DHA}+803 \mathrm{mg} / \mathrm{d} \\
\text { EPA }\end{array}$ & $\begin{array}{l}\text { High DHA eggs }(133 \mathrm{mg} \\
\text { DHA/egg): } 137 \mathrm{mg} / \mathrm{d} \\
\text { mean DHA intake }\end{array}$ & Algal DHA $400 \mathrm{mg} / \mathrm{d}$ & $\begin{array}{l}\text { Basic supplement (vita- } \\
\text { mins and minerals) + } \\
\text { FOS + DHA }(200 \mathrm{mg} / \mathrm{d})\end{array}$ & $\begin{array}{l}\text { Fish oil }(4.5 \mathrm{~g} / \mathrm{d}): 790 \mathrm{mg} / \mathrm{d} \text { DHA } \\
\quad+620 \mathrm{mg} / \mathrm{d} \text { EPA }\end{array}$ \\
\hline Control & $\begin{array}{l}\text { Control 1: olive oil }(4 \mathrm{~g} / \mathrm{d}) \text { - } \\
\text { Control 2: not sup- } \\
\text { plemented }\end{array}$ & Corn oil $(10 \mathrm{ml} / \mathrm{d})$ & $\begin{array}{l}\text { Ordinary eggs }(33 \mathrm{mg} \\
\text { DHA/egg): } 34 \mathrm{mg} / \mathrm{d} \\
\text { mean DHA intake }\end{array}$ & Olive oil & $\begin{array}{l}\text { - Control 1: basic sup- } \\
\text { plement + FOS } \\
\text { - Control 2: basic } \\
\text { supplement }\end{array}$ & Olive oil $(4.5 \mathrm{~g} / \mathrm{d})$ \\
\hline $\begin{array}{l}\text { Total ran- } \\
\text { domized }\end{array}$ & 533 & 590 & 350 & 1094 & 144 & 122 (allocated after delivery) \\
\hline Results & $\begin{array}{l}\text { Longer gestation }(4 \mathrm{~d}) \text { and } \\
\text { higher birth weight } \\
(107 \mathrm{~g}) \text { in fish oil group } \\
\text { compared with olive oil } \\
\text { group. }\end{array}$ & $\begin{array}{l}\text { Neither infant birth weight nor } \\
\text { gestation length increased } \\
\text { when women were sup- } \\
\text { plemented with } n-3 \text { PUFA. } \\
\text { No differences in weight } \\
\text { between the groups at } 6 \text { wk } \\
\text { or } 3 \text { mo after birth. }\end{array}$ & $\begin{array}{l}\text { Longer gestation (6-d) with } \\
\text { increased DHA intake. } \\
\text { Slightly heavier infants } \\
\text { at birth (NS) }\end{array}$ & $\begin{array}{l}\text { No overall effect of } \\
\text { DHA treatment in } \\
\text { mean gestational } \\
\text { age or birth } \\
\text { weight. } \\
\text { Offspring of pri- } \\
\text { migravid women } \\
\text { who received DHA } \\
\text { were heavier at } \\
\text { birth. }\end{array}$ & $\begin{array}{l}\text { No difference in birth } \\
\text { weight } \\
\text { No effect of DHA } \\
\text { supplementation on } \\
\text { infant weight or BMl at } \\
1 \text { or } 3 \text { mo after birth. }\end{array}$ & $\begin{array}{l}\text { No effect of DHA supplemen- } \\
\text { tation on infant weight or BMI } \\
\text { at } 2 \text { or } 4 \text { mo after birth. }\end{array}$ \\
\hline
\end{tabular}

FOS, fructooligosaccharide. 
wk of gestation to the end of third month of lactation. Given that there were no differences between the first two groups in any of the outcome measures, and considering that the aim of the trial was to investigate the effects of the DHA supplements on growth, those two groups not receiving DHA were pooled to create one control group for subsequent analysis. There were no significant differences between the DHA and control group in infants weight at birth. It should be noted, though, that this trial focused on the effect of DHA on growth from birth onwards. Then, analysis for possible confounders of birth weight was not done (or reported).

In the study conducted by Smuts et al. ${ }^{(31)}$ in United States, 350 women between $24-28$ wk of gestation were randomized to receive either DHA-enriched eggs (133 mg DHA/egg, $n$ 176) or ordinary eggs (33 mg DHA/egg, $n$ 174) until delivery. Egg intake per week was (mean (SD)) $7 \cdot 2$ (3.4) in the experimental group and $7.3(3.4)$ in the control group. Hence, DHA intake was approximately $137 \mathrm{mg} / \mathrm{d}$ in the DHA-supplemented groups and $34 \mathrm{mg}$ in the control groups (ordinary eggs). After controlling for a number of statistically influential variables, the authors found a 6-day longer period of gestation when DHA intake was increased during the last trimester of pregnancy (experimental group). Similarly, once addressed confounders that significantly influenced birth weight, infants in the high-DHA egg group tended to be heavier than those in the ordinary-egg group, but the difference was not significant. If it was not for the "prefixed" gestational age, it is likely that some clear effect on birth weight would have existed. These results are, thus, concordant with those by Olsen et al. ${ }^{(30)}$ and support the hypothesis that any $n-3$ PUFA effects on birth weight are likely mediated, at least in part, by an influence on the gestation length. Moreover, in the trial by Smuts et $a l .{ }^{(31)}$, the effect of DHA supplementation on this parameter is achieved with a much smaller daily dose of $n-3$ PUFA $(137 \mathrm{mg} / \mathrm{d}$ DHA) compared with those used by Olsen et $a l .{ }^{(30)}(920 \mathrm{mg} / \mathrm{d}$ DHA plus $1280 \mathrm{mg} / \mathrm{d} \mathrm{EPA})$. This may be related to a poor baseline DHA status of participants in the study by Smuts et $a l{ }^{(31)}$, as shown by studies conducted in United States ${ }^{(35)}$.

In the recent study by Ramakrishnan et al. ${ }^{(32)}, 1094$ Mexican women were randomly assigned to receive $400 \mathrm{mg}$ DHA derived from an algal source ( $n$ 547) or a placebo (olive oil, $n$ 547) daily from $18-22$ wk of gestation to delivery. Intention-to-treat analysis showed no differences between the control and DHA group in gestational age (mean (SD): 39.1 (1.7) and 39.9 (1.9) weeks, respectively) or birth weight (mean (SD): $3.20(0.47)$ and $3.21(0.45) \mathrm{kg}$, respectively). Interestingly, it was found heterogeneity in that the offspring of primigravid women who received DHA were heavier at birth than the offspring of primigravidae who received placebo. Given that the infant sex ratio, gestational age at entry, supplement consumption and dietary intakes of $n-3$ and n-6 PUFA (both at entry and delivery, as assessed by a food frequency questionnaire) did not differ by gravidity, the authors suggested that the typical trend among primigravid women to have smaller infants than multigravidae could have been somehow counteracted by DHA supplementation.
The lack of effect of DHA supplementation in Mexican women (except for primigravidae) ${ }^{(32)}$ is difficult to reconcile with some of the previous studies. For example, the intervention period was longer than in the trials by Olsen et al. ${ }^{(30)}$ and Smuts et $a l .{ }^{(31)}$. The dose of DHA supplement in the study by Ramakrishnan et al $^{(32)}$ was in the low range ( $400 \mathrm{mg} \mathrm{DHA} / \mathrm{d}$ ) but such dose (that, in fact, nearly tripled the dose supplied by Smuts et al. ${ }^{(31)}$ ) should have been expected to induce a marked response had the participants showed a poor DHA status at the beginning, and this was exactly the case. Evaluation of dietary intakes of fatty acids with the use of a food frequency questionnaire revealed that less than $20 \%$ of the women consumed fish, resulting in a median dietary intake of DHA at recruitment of only $55 \mathrm{mg} / \mathrm{d}$. In the attempt to explain the lack of an overall effect of supplementation on birth outcomes, the authors point out that the true DHA status of the study sample may have been better than suggested by DHA intake data, based on the fact that intake of $18: 3 n-3$ was very high (median $1480 \mathrm{mg} / \mathrm{d}$ ).

Of great importance are the issues related to trial quality. The trial by Ramakrishnan et $a l .{ }^{(32)}$, in addition to almost doubling or even tripling the sample size of other trials, is considered of high quality respect to the quality of the methods and the quality of reporting results: randomization, allocation concealment, blinding of participants and all involved personnel, intention-to-treat analysis and completeness of follow-up. In contrast, other trials, even though fulfilled all criteria for method quality according to the Jadad score ${ }^{(9)}$, showed some weakness in specific aspects. For example, in the trial by Olsen et al. ${ }^{(30)}$, masking of the type of oil supplemented was not completely successful, being much more effective for olive oil than for fish oil. In addition, some subjects may have gained the impression that fish oil was beneficial, and consequently, some women in both the no-oil and fish oil group admitted after delivery that they had either self-supplemented with fish oil or had increased their fish intake during the trial period. The main weakness in the study by Smuts et al. ${ }^{(31)}$ was that allocation concealment was unclear (not reported). In the study by Helland et al. ${ }^{(4)}$, apart from problems with the study design (choice of an appropriate control group), the percentage of participants included in the analysis was quite low (approximately 58\% at birth and $49 \%$ in the final analysis).

In summary, the results of the four trials in which the primary outcome was birth weight/size make it impossible to draw robust conclusions. The trials by Olsen et al. ${ }^{(30)}$ and Smuts et $a l{ }^{(31)}$ seem to suggest that maternal $n-3$ PUFA supplementation is associated with a modest increment in the duration of pregnancy and, consequently, in birth weight. Two other trials, however, report no effect. In the trial by Helland et $a l .{ }^{(4)}$ this may be related to the choice of the control group and to a high attrition rate leading to loss of statistical power. This is not, however, the case for the study by Ramakrishnan et al. ${ }^{(32)}$ a large, high quality trial that showed a lack of an overall effect of DHA supplementation, except for primigravidae.

A second question to analyse is whether or not $n$-3 PUFA supplementation during pregnancy and/or lactation affects 
infant growth from birth. Three trials have to be considered $^{(4,7,8)}$. In two of the trials the intervention extended from $18^{(4)}$ or $21^{(8)}$ week of pregnancy to 3 months postpartum (see Table 2). In the third trial ${ }^{(7)}$, maternal $n$-3 PUFA supplementation was provided only during the first 4 months of lactation. In two trials ${ }^{(4,7)}$, fish oil was given to participants whereas DHA only (prepared from fish oil) was supplied in the third one ${ }^{(8)}$. Doses of $n-3$ PUFA in the supplemented groups ranged from $200 \mathrm{mg} / \mathrm{d} \mathrm{DHA}^{(8)}$ to $2000 \mathrm{mg} / \mathrm{d}$ $(1183 \mathrm{mg} / \mathrm{d}$ DHA plus $803 \mathrm{mg} / \mathrm{d}$ EPA). All studies included a control group, which was different in each one.

In the study by Helland et $a l .{ }^{(4)}$ (see above), the supplementation with cod liver oil or corn oil that started at week 18 of gestation, continued until the third month of lactation. A limitation of this trial is that growth measures (weight) were no recorded directly by research personnel. Instead, mothers copied the records at local health care centres and mailed the data to the authors. Out of 590 randomized (301 to cod liver oil and 289 to corn oil) only 341 mothers were available at birth and only growth records from 288 infants were received (152 from cod liver oil group and 136 from corn oil group). At 3 months of age (end of supplementation), 213 infants were exclusively breastfed in addition to 29 infants who were partially breastfed. The content of long-chain fatty acids in breast milk reflected the composition of the supplements: arachidonic acid was higher in the corn oil group and $n-3$ PUFA (EPA and DHA) were higher in the cod liver oil group. No difference in infant weight was found at 3 weeks or 3 months after birth between the study groups. An issue to take into account in this trial is that, following Norwegian guidelines of infant nutrition that recommend $5 \mathrm{ml}$ of cod liver oil daily for infants from 4 weeks of age, mothers of 130 infants among those followed up until the $3^{\text {rd }}$ month of lactation admitted to have given cod liver oil to their infants, this introducing an additional interfering factor.

Bergmann et al. ${ }^{(8)}$ randomized pregnant women to a DHA supplement $(200 \mathrm{mg} / \mathrm{d})$ from $21 \mathrm{wk}$ of gestation to the end of third month of lactation. A combined control group not receiving DHA was used (see above). Out of 144 women enrolled, only 89 were available for infant's anthropometrics 1 month after birth and this number was further reduced to 87 at the end of the third month of lactation. During the study period, there were no significant differences in breastfeeding rates between the experimental (DHA) and control groups, $80 \%$ of the infants being exclusively breastfed up to three months. No effect of DHA supplementation on infant weight or BMI was revealed at 1 or 3 months of age.

In the study by Lauritzen et al. ${ }^{(7)}$, maternal $n$-3 PUFA supplementation was confined to the lactation period (until $4^{\text {th }}$ month postpartum). A total of 122 Danish women with fish intake below the median $(<0.40 \mathrm{~g} / \mathrm{d}$ long-chain $n-3$ PUFA) were allocated after delivery to receive $4.5 \mathrm{~g} / \mathrm{d}$ of either fish oil (that provided $790 \mathrm{mg}$ DHA/d plus $620 \mathrm{mg}$ $\mathrm{EPA} / \mathrm{d}, n$ 62) or olive oil (control group, $n$ 60). The oils were in microencapsulated form and concealed in muesli bars or cookies. As an alternative, women were offered the supplements as capsules containing olive oil (4/d) or fish oil ( $4 \mathrm{~g} / \mathrm{d}$ providing $990 \mathrm{mg} / \mathrm{d}$ DHA plus $360 \mathrm{mg} / \mathrm{d}$ EPA).
The distribution of the three forms of supplements did not differ among treatments. Out of the initial 122 women, 104 were available for infant anthropometric measurements at 2 months, and 100 completed the intervention period of 4 months and provided anthropometric infant data (53 fish oil group and 47 control group). Fish oil supplementation of lactating mothers did not affect infant weight or BMI at 2 or 4 months of age. The sex ratio and degree of breastfeeding, which have been shown to be associated with infant growth $^{(36)}$, were not equally distributed in the randomized groups. However, inclusion of these variables in the analysis did not modify the results.

These results seem to indicate that supplementation of pregnant and/or lactating women do not affect offspring weight during the intervention. This occurred both if the supplementation commenced during pregnancy ${ }^{(4,8)}$ or was exclusively confined to the lactation period ${ }^{(7)}$. This indication, however, should be viewed with caution. The sample size in some trials was small ${ }^{(7,8)}$. Marked variability in the characteristics of study populations, baseline $n$ - 3 PUFA status ${ }^{(4,7)}$, and the interventions tested may have decreased the sensitivity for detecting possible effects. The quality of the methods and reported results varied. Potential limitations include no (or unclear) intention-to-treat analysis ${ }^{(4,7,8)}$, unclear allocation concealment ${ }^{(4,7,8)}$, high attrition rates ${ }^{(4,8)}$ and problems with blinding ${ }^{(4,7)}$. The findings are, therefore, likely to be affected to various degrees by selection, attrition or performance biases. In some cases ${ }^{(4)}$ the choice of a control group that was no inert (corn oil) could have interfered. Nevertheless, a lack of effect of $n$-3 PUFA on infant's weight or BMI at short term, i.e., during the intervention, does not exclude that a longer-term effect may exist. In fact, one of the included trials $^{(7)}$ showed an effect of fish oil supplementation on body composition that was apparent $2 \mathrm{y}$ after completion of the intervention. During the intervention and at the 9-mo follow-up, there was no difference in BMI between the groups. The authors suggested that the late onset of the effect and its persistence after control for energy intake could indicate some kind of programming effect.

Several concerns regarding the safety of increasing $n-3$ PUFA intake during pregnancy or lactation have been raised. Of the six trials included in this part of the review, adverse effects were reported in only four ${ }^{(4,30-32)}$. Olsen et al. ${ }^{(30)}$ indicated that the proportion of women who reported belching and unpleasant taste attributed to the oil capsules was significantly greater in the fish oil group than in the olive oil or no oil groups. In this study, blood loss at delivery was greatest in the fish oil group, reaching statistical significance as compared with the olive oil group. There were no significant differences between groups in other possible side effects of the fish oil, such as prolongation of labour or the need for a surgical delivery. In the study by Helland et al. ${ }^{(4)}$, most of the women who withdrew did so because of feeling discomfort taking the oil, but there were no differences in the withdrawal rates between the groups. Also, estimated blood loss was similar in the two groups. Smuts et al. ${ }^{(31)}$ reported that the proportion of mothers who experienced one or more adverse events was significantly higher in the regular 
egg group than in the DHA-supplemented group. Gynecologic adverse events in general, and labour-related adverse events in particular, were less common among subjects in the DHA-supplemented group. The two groups had the same number of total serious adverse events (death, life-threatening events, etc). Rates of adverse events or serious adverse events were similar in the two groups of neonates. Ramakrishnan et al. ${ }^{(32)}$ found no significant differences in the total number of adverse events or serious adverse events by treatment group in mothers or their offspring. Side effects such as nausea, headache, and swelling were common. Specifically, the proportions of women who reported ever vomiting were $23.8 \%$ and $26.9 \%$ in the control and DHA groups, respectively; the proportions reporting ever having nausea were $30.3 \%$ and $33.7 \%$, respectively. Vaginal bleeding or fainting was reported by less than $10 \%$ of women and this proportion did not differ by treatment group.

\section{Overall conclusion}

Taking into account both the adult studies and those performed in pregnant/lactating women, this systematic review highlights the paucity of conclusive data to evaluate the effect of $n-3$ PUFA on body weight. This may be attributed to important differences in the baseline characteristics of participants, experimental designs, and source and dose of $n-3$ PUFA. There is a need for additional randomized controlled clinical trials with harmonized variables to address this knowledge gap.

\section{Acknowledgements}

The authors state that there are no conflicts of interest. EMV and MDY performed the literature search. EMC wrote the draft of the studies in adults and MDY the draft of studies in pregnant/lactating women. EMV and MDY discussed and revised the drafts and wrote the final version together. This research received no specific grant from any funding agency in the public, commercial or not-for-profit sectors.

\section{References}

1. Trowman R, Dumville JC, Hahn S, et al. (2006) A systematic review of the effects of calcium supplementation on body weight. Br J Nutr 95, 1033-1038.

2. Takahashi $\mathrm{Y} \&$ Ide $\mathrm{T}$ (2008) Dietary $n$-3 fatty acids affect mRNA level of brown adipose tissue uncoupling protein 1 , and white adipose tissue leptin and glucose transporter 4 in the rat. Br J Nutr 84, 175-184

3. Ruzickova J, Rossmeisl M, Prazak T, et al. (2004) Omega-3 PUFA of marine origin limit diet-induced obesity in mice by reducing cellularity of adipose tissue. Lipids 39, 1177-1185.

4. Helland IB, Saugstad OD, Smith L, et al. (2001) Similar effects on infants of $n-3$ and $\mathrm{n}-6$ fatty acids supplementation to pregnant and lactating women. Pediatrics 108, E82.

5. Drouillet P, Kaminski M, De Lauzon-Guillain B, et al. (2009) Association between maternal seafood consumption before pregnancy and fetal growth: evidence for an association in overweight women. The EDEN mother-child cohort. Paediatr Perinat Epidemiol 23, 76-86.
6. Innis SM (2007) Human milk: maternal dietary lipids and infant development. Proc Nutr Soc 66, 397-404.

7. Lauritzen L, Hoppe C, Straarup EM, et al. (2005) Maternal fish oil supplementation in lactation and growth during the first 2.5 years of life. Pediatr Res 58, 235-242.

8. Bergmann RL, Bergmann KE, Haschke-Becher $\mathrm{E}$, et al (2007) Does maternal docosahexaenoic acid supplementation during pregnancy and lactation lower BMI in late infancy? J Perinat Med 35, 295-300.

9. Jadad AR, Moore RA, Carroll D, et al. (1996) Assessing the quality of reports on randomized clinical trials: Is blinding necessary? Controlled Clin Trials 17, 1-12.

10. DeFina LF, Marcoux LG, Devers SM, et al. (2011) Effects of omega-3 supplementation in combination with diet and exercise on weight loss and body composition. Am J Clin Nutr 93, 455-462.

11. Thorsdottir I, Tomasson H, Gunnarsdottir I, et al. (2007) Randomized trial of weight-loss-diets for young adults varying in fish and fish oil content. Int J Obes (Lond) 31, 1560-1566.

12. Kabir M, Skurnik G, Naour N, et al. (2007) Treatment for 2 mo with $n 3$ polyunsaturated fatty acids reduces adiposity and some atherogenic factors but does not improve insulin sensitivity in women with type 2 diabetes: a randomized controlled study. Am J Clin Nutr 86, 1670-1679.

13. Hill AM, Buckley JD, Murphy KJ, et al. (2007) Combining fish-oil supplements with regular aerobic exercise improves body composition and cardiovascular disease risk factors. Am J Clin Nutr 85, 1267-1274.

14. Krebs JD, Browning LM, McLean NK, et al. (2006) Additive benefits of long-chain $n-3$ polyunsaturated fatty acids and weight-loss in the management of cardiovascular disease risk in overweight hyperinsulinaemic women. Int $J$ Obes (Lond) 30, 1535-1544.

15. Neilson HK, Robson PJ, Friedenreich CM, et al. (2008) Estimating activity energy expenditure: how valid are physical activity questionnaires? Am J Clin Nutr 87, 279-291.

16. Trabulsi J \& Schoeller DA (2001) Evaluation of dietary assessment instruments against doubly labeled water, a biomarker of habitual energy intake. Am J Physiol Endocrinol Metab 281, E891-E899.

17. Cottin SC, Sanders TA \& Hall WL (2011) The differential effects of EPA and DHA on cardiovascular risk factors Proc Nutr Soc 70, 215-231.

18. Martins JG (2009) EPA but not DHA appears to be responsible for the efficacy of omega-3 long chain polyunsaturated fatty acid supplementation in depression: evidence from a meta-analysis of randomized controlled trials. J Am Coll Nutr 28, 525-542.

19. Parra D, Ramel A, Bandarra N, et al. (2008) A diet rich in long chain omega- 3 fatty acids modulates satiety in overweight and obese volunteers during weight loss. Appetite 51, 676-680.

20. Innis SM (1991) Essential fatty acids in growth and development. Prog Lipid Res 30, 39-103.

21. Koletzko B (1998) Lipid supply and metabolism in infancy. Curr Opin Clin Nutr Metab Care 1, 171-177.

22. Larqué E, Demmelmair H, Berger B, et al. (2003) In vivo investigation of the placental transfer of 13C-labeled fatty acids in humans. $J$ Lipid Res 44, 49-55.

23. Al MD, van Houwelingen AC, Kester AD, et al. (1995) Maternal essential fatty acid patterns during normal pregnancy and their relationship to the neonatal essential fatty acid status. Br J Nutr 74, 55-68.

24. Berghaus T, Demmelmair H \& Koletzko B (2000) Essential fatty acids and their long-chain polyunsaturated metabolites 
in maternal and cord plasma triglycerides during late gestation. Biol Neonate 77, 96-100.

25. Olsen SF \& Joensen HD (1985) High liveborn birth weights in the Faroes: a comparison between birth weights in the Faroes and in Denmark. $J$ Epidemiol Community Health 39, 27-32.

26. Elias SL \& Innis SM (2001) Infant plasma trans, $n-6$, and $n-3$ fatty acids and conjugated linoleic acids are related to maternal plasma fatty acids, length of gestation, and birth weight and length. Am J Clin Nutr 73, 807-814.

27. Jensen RG (1999) Lipids in human milk. Lipids 34, 1243-1271.

28. Jensen CL, Maude M, Anderson RE, et al. (2000) Effect of docosahexaenoic acid supplementation of lactating women on the fatty acid composition of breast milk lipids and maternal and infant plasma phospholipids. Am J Clin Nutr 71, 292S-299S.

29. Decsi T \& Koletzko B (2005) n-3 Fatty acids and pregnancy outcomes. Curr Opin Clin Nutr Metab Care 8, 161-166.

30. Olsen SF, Sorensen JD, Secher NJ, et al. (1992) Randomized controlled trial of effect of fish-oil supplementation on pregnancy duration. Lancet 339, 1003-1007.

31. Smuts CM, Huang M, Mundy D, et al. (2003) A randomized trial of docosahexaenoic acid supplementation during the third trimester of pregnancy. Obstet Gynecol 101, 469-479.

32. Ramakrishnan U, Stein AD, Parra-Cabrera S, et al. (2010) Effects of docosahexaenoic acid supplementation during pregnancy on gestational age and size at birth: randomized, double-blind, placebo-controlled trial in Mexico. Food Nutr Bull 31, S108-S116.

33. Matorras R, Perteagudo L, Sanjurjo P, et al. (1999) Intake of long chain $\mathrm{w} 3$ polyunsaturated fatty acids during pregnancy and the influence of levels in the mother on newborn levels. Eur J Obstet Gynecol Reprod Biol 83, 179-184.

34. Xiang M, Lei S, Li T, et al. (1999) Composition of long chain polyunsaturated fatty acids in human milk and growth of young infants in rural areas of northern China. Acta Paediatr 88, $126-131$.

35. Henderson RA, Jensen RG, Lammi-Keefe CJ, et al. (1992) Effect of fish oil on the fatty acid composition of human milk and maternal and infant erythrocytes. Lipids $\mathbf{2 7}$, 863-869.

36. Lauritzen L, Jørgensen MH \& Michaelsen KF (2004) Testretest reliability of swept visual evoked potential measurements of infant visual acuity and contrast sensitivity. Pediatr Res 55, 701-708. 